\title{
A Concise Study on Shearing Operation in Metal Forming
}

\author{
Omolayo M. Ikumapayi ${ }^{1 *}$, Sunday A. Afolalu ${ }^{2}$, Olawale S. Fatoba ${ }^{3}$, Rasaq A. Kazeem ${ }^{4}$, Adedotun A. Adetunla ${ }^{1}$, Samuel O. \\ Ongbali ${ }^{2}$ \\ ${ }^{1}$ Department of Mechanical and Mechatronics Engineering, Afe Babalola University, Ado Ekiti, 360101, Nigeria \\ ${ }^{2}$ Department of Mechanical Engineering, Covenant University, Ota, 112233, Nigeria. \\ ${ }^{3}$ Department of Mechanical Engineering Science, University of Johannesburg, 2006, South Africa \\ ${ }^{4}$ Department of Mechanical Engineering, University of Ibadan, 200005, Nigeria
}

\begin{abstract}
This study outlines the recent developments in metal forming processes, focusing mainly on the shearing process. A summary of the background of the shearing process is given to give perspective on how such a process has changed over time. It explains what shearing operations are and how the shearing process is operated in metal forming. While also outlining the difference between shearing, slitting, punching, notching, and blanking processes, and the advantages and disadvantages of the shearing process are detailed. Different types of modern shearing machines are documented. The ways of ensuring the optimal functionality of the shearing machine and how the shearing operation has improved the manufacturing products were scripted. Three cases were given on the recent advancement in the use of shearing operation. Recommendations on how to improve efficiency in shearing metal forming are specified with relevance to the theory and a conclusion is drawn.
\end{abstract}

\section{Introduction}

Metal forming is a process where sheets or tubes are deformed by a die to form the desired shape, the geometries are used to produce structural components in many industries [1]. Shear forming may only be used in ductile materials with lengths that are not too small, it is based on the principle of plastic deformation hence deciding whether this process is suitable for an application, one must have a clear understanding of shearing operation [2]. Furthermore, a metal can be formed by either applying both compressive and tensile stresses(bending) or shear stresses where friction between the die and the metal induces these stresses at the interface [3, 4]. Shear forming is an example of metal forming where the blank workpiece having a circular or rectangular shape is placed between the mandrel and chuck of the spinning machine, in this case, shear stresses occur at the interface of the mandrel and the metal sheet due to spinning [5]. Metal spinning is one of the oldest forming processes where there is no material loss however, other similar forming processes were introduced such as deep drawing [5]. From shear forming being known as the art of potting clay using manual-powered potters' wheel in ancient Egypt to it being an engineering manufacturing technique in the 20th century, many developments are still being discovered [5].

Shearing is used to cut metal sheets because it is faster and more cost-effective, it has been used since the start of industries [6]. Ken-ichiro developed a review of someof the Shearing Processes of High Strength Steel Sheets and the cutting methods in engineering in 2020 and focused more on ductile metal sheets and using a guillotine (which is one of the angled cutters) [6]. Early in the twentieth century, the force measurement analysis on many metals was made and some of the metals that were used were carbon steel and it was conducted by Izod in 1906 [6]. AlQureshi also conducted experiments similar to the ones mentioned above, that is, analysis of simultaneous sheet metal forming operations using elastomer technique. Symmetry double shearing with parallel tools was employed and they also focus on the clearance with respect to the applied forces on the metal sheet, then Crane studied shapes that occur after shearing and in 2002 [7].

Shearing is the mechanical cutting of materials, often used to prepare content for subsequent operations, without the forming of chips or the use of burning or melting, and its performance helps to ensure the accuracy and consistency of the final product [7]. Hambli also got more studies on cutting tool wear [8]. Shearing is also referred to as sheet metal cutting. When a shearing force is applied such that the shearing stress exceeds the ultimate shear strength of the material will fail to separate at the location of application [8]. The shearing process makes use of two tools namely a punch and a die (upper and lower blade) which are located above and below the sheet (figure 1) [8]. The distance between the lower blade and upper blade (clearance) range between $2 \%$ and $10 \%$ of the

*Correspondingauthor:ikumapayi.omolayo@abuad.edu.ng 
sheet thickness which is dependent on the material Mechanical properties such as shearing strength of the sheet, the main cause of this clearance is to better cut a sheet without ruining a material and make a material to deform plastically [8].

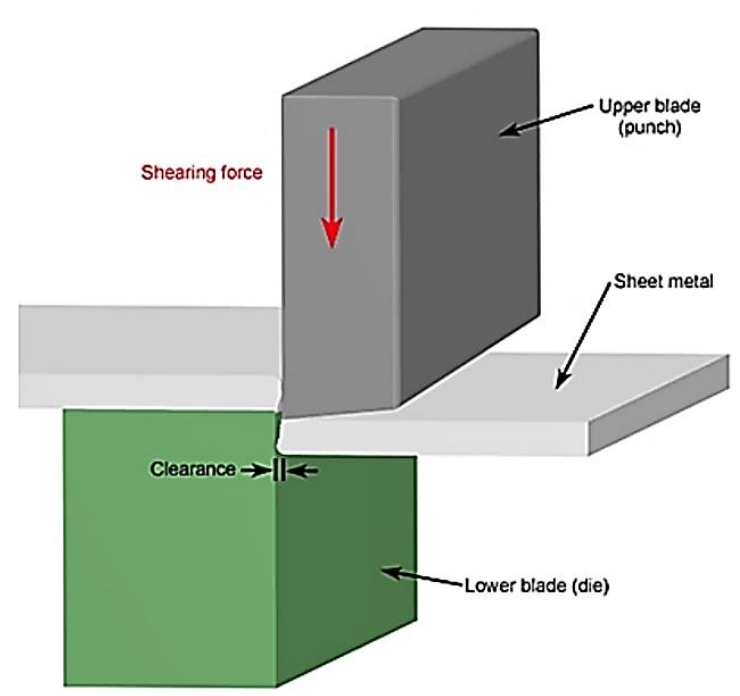

Fig. 1. Shear of metal sheet [8]

\section{Shearing Operation}

When two blades cut a piece, the process is called shearing [7], but the process is called blanking, piercing, notching, or trimming when the blades are at an angle, while both are referred to as shearing operations in terms of tool design and material behaviour [7]. A common model of shearing is shown in Figure 2. When the punch forces the metal onto the workpiece, it flows through the die and assumes the shape of the die, since the clearance between the two tools is limited, usually between 5 and 10 per cent of the thickness of the metal being cut, the deformation takes place as a highly localized shear [7]. Whenever the actual shearing action is performed in a compressive setting, the fracture is minimized, and the total fraction of the smooth edge is increased. No fracture may occur when a certain pressure is reached, and the entire surface is smooth deformed metal. The metal sheet is placed on top of the die and a certain clearance from the die there is a punch (cutter on top).
The force is applied to the metal sheet by a punch such that the force causes shear between the die and the punch which is the actual cutting area between the lower and upper blades [8].

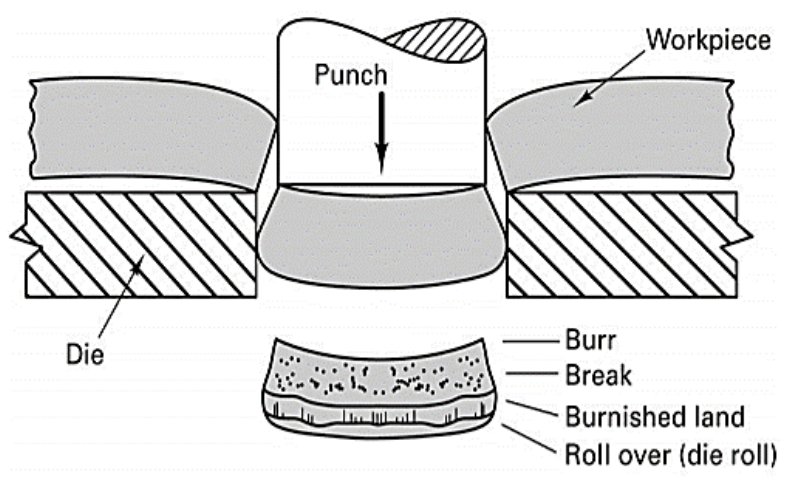

Fig. 2. Simple blanking with a punch and die [7].

\subsection{Shearing and Punching Operations}

In most cases, shearing operation and punching operation are taken to be the same whilst they are not. The concept of shearing is related to the way force is applied and mechanical deformation nevertheless is also considered as manufacturing process [9]. The difference between shearing and punching operations lies in "true" forming operations because they tend to cut instead of deforming material to generate shapes different from the previous ones. Shearing processes tend to utilize offset with the aim of opposing forces to allow material separation to venture into multiple sections as illustrated in Figure 3 [10]. A straightforward example of this kind of operation is the action of scissors in cutting and it is also alluding to as shears. The blades in opposition lead to cut material to separate from a direct path. Most scissors have a straight cut and when cutting contours, they need to angle. Manipulation of material is often not allowed on the shearing operation done on metals. Cutting edges shapes dictate the final part shape [10]. The following are forms of Shearing techniques: (i) simple Shearing(ii) Punching (iii) Slitting (iv) Blanking (v) Notching (vi) Cut-off (vii) Nibbling (viii) Shaving (ix) Trimming (x) Dinking (xi) Lancing (xii) Fine blanking
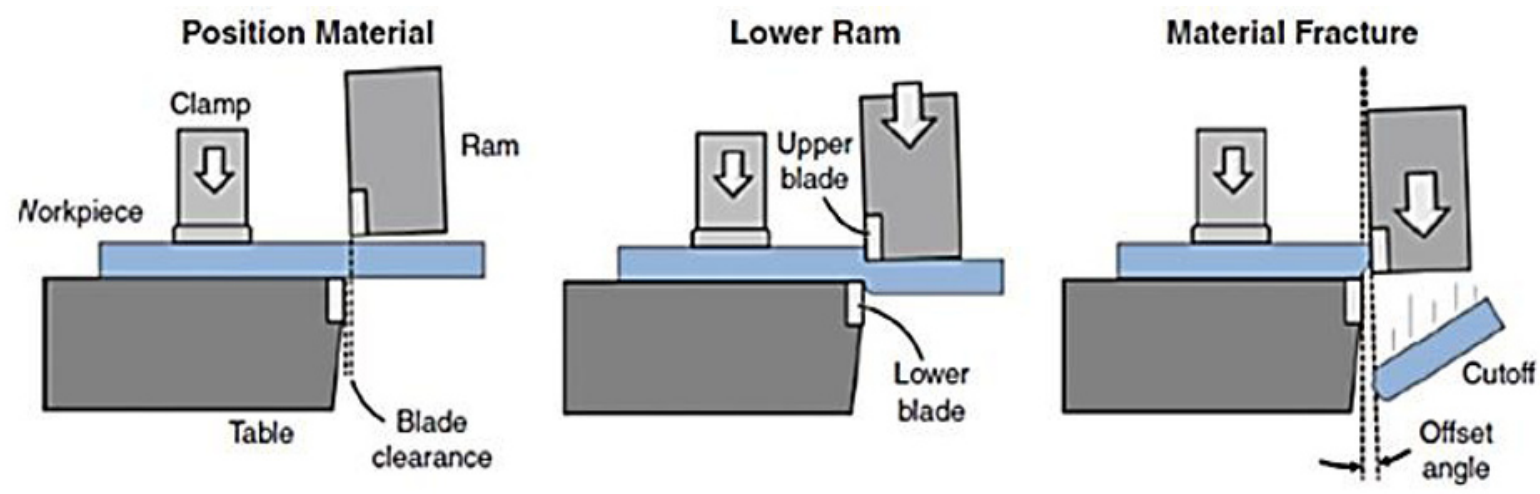

Fig. 3. Opposing forces that cause fracture [9] 
Shearing is considered as a process that utilizes opposition of forces to cause a fracture in the material that happens to be down a specific path. Most of the time this is straight but curved cuts are also used. Punching happens when the cutting path happens to be closed. If shearing can be compared to scissors cutting, then punching operation is like a hole punch. The hole punch makes an internal characteristic that allows removal of the material section. Taking loyalty cards as an example, the store can decide to use a hole punch that is shaped uniquely in this relation punching operations done in a metal can be performed with more complex shapes. Punching and shearing operations are alike in many ways, but the action of cutting occurs on surfaces that are curved and form a whole part or feature as illustrated in Figure 4 [11].

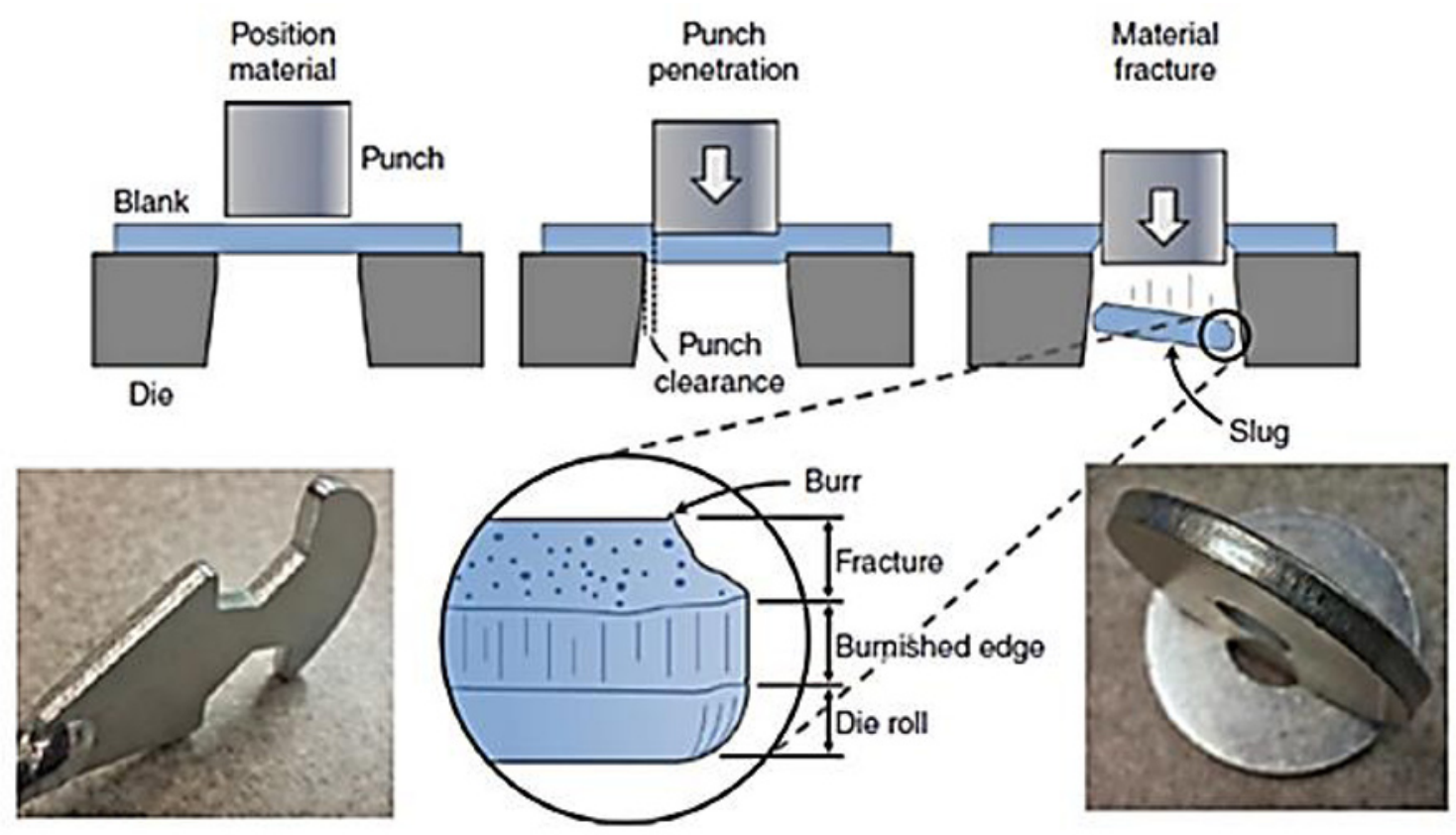

Fig. 4. The general process of shearing and punching [11]

In general, the process of shearing and punching include opposition of forces that are applied to a material leading to tool penetration and workpieces fractures combining. The characteristics of the material and the geometry of a tool influence the outcome expected on the processes [11]. Different shapes can be generated ranging from basic shapes like the circular part on the far right in Figure 4 to more complex shapes such as the one on the left.

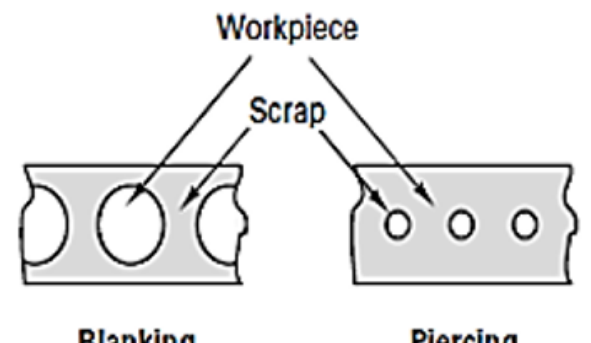

(a)

Blanking

Piercing

\subsubsection{Slitting}

This is a shearing system used to cut sheet metal coils into several narrow width rolls, with the circumference of mating grooves, the shearing blades are of spherical type (See Figure 5). The method is continuous and can be done rapidly and economically by raising the ribs of one roll with fixed groves on the other [7]. Compared to those obtained from alternative cutting methods [7], the resulting strips are precise and reliable.
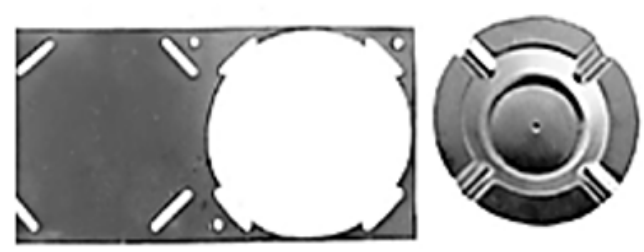

(b)

Fig. 5. (a) Illustrations showing the distinction between blanking and piercing, (b) (Left to right) Piercing, lancing, and blanking precede the forming of the final ashtray. The small round holes assist positioning and alignment [7] 


\subsubsection{Blanking}

Blanking is a one-step operation in which the cutting blade cuts through a sheet metal separating the desired piece termed the blank from the surrounding stock (refer to figure 6) [12]. The blanking process makes use of a punch, die press and sheet metal stock (refer to figure 7). Both the punch and die cavity in this process possess the form of the anticipated shape. The sheet metal is positioned on top of the blanking press of the die. Under operation, the die is released in a downward motion at very high speeds using a hydraulic press drive. The clearance of about $10-20 \%$ allows a smooth downward fall. On impact, the sheet metal quickly bends and fractures, the stock will then plummet into the gap of the die. The process is so swift such that 1000 strokes/minute is performed by the blanking press (refer to figure 7) [13].
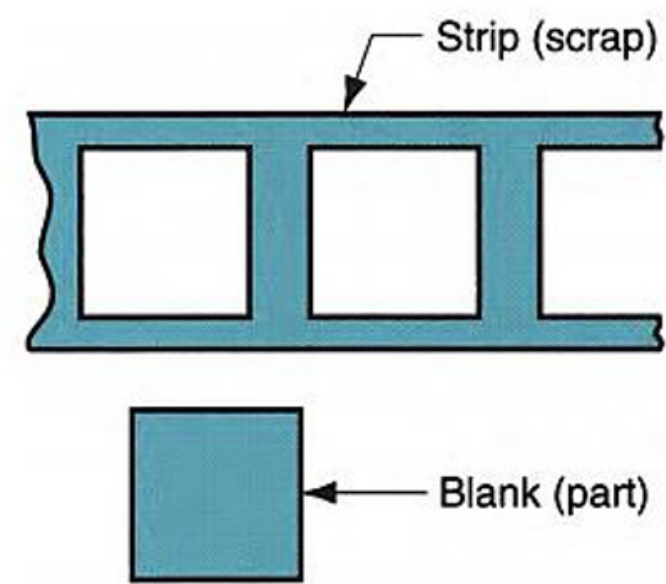

Fig. 6. illustration of blank operation in metal workpiece [14]

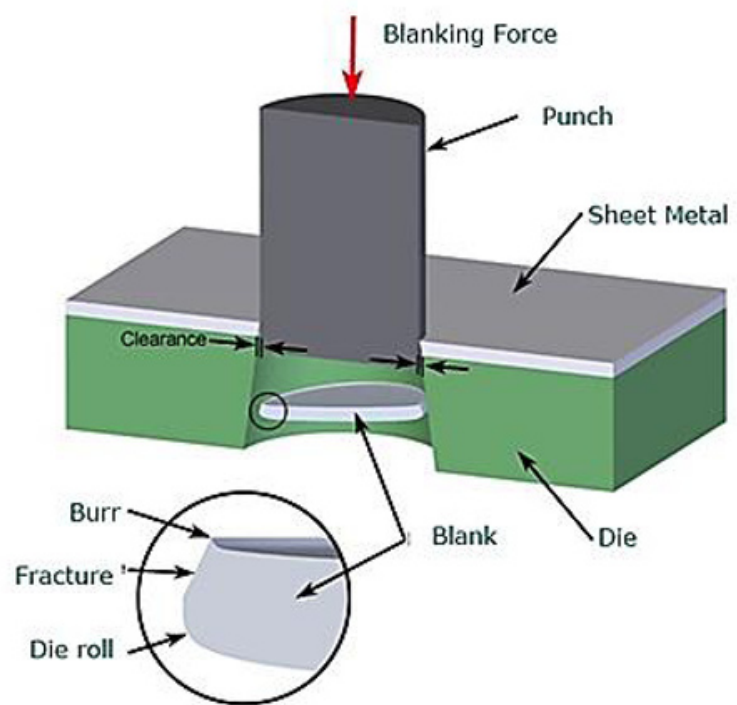

Fig. 7. Illustration of blanking process in sheet metals [13].

\subsubsection{Fine blanking}

Fine blanking is a specific type of blanking wherein the blank is sheared from the sheet stock with the help of three distinct powers as illustrated in Figure 8, creating a higher flatness portion, a smoother edge with reduced burrs, and tolerances as close as \pm 0.0003 [13]. Most of the fine blanking method and configuration is very much like a traditional blanking. The sheet stock continues to be positioned within a hydraulic press over a blanking die, and a blanking punch then impacts the sheet to eliminate the blank. This is achieved, as mentioned above, through the 3 forces software [13].

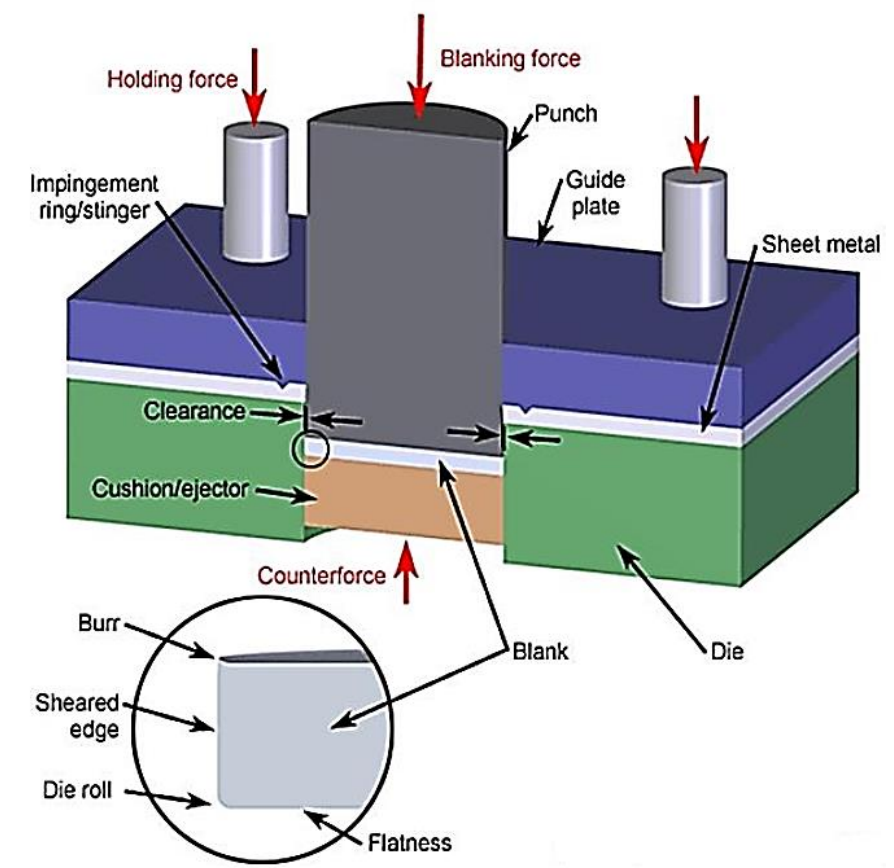

Fig. 8. Fine blanking illustration [13].

\subsubsection{Notching}

Notching is a low production manual shearing process where a scrap piece is removed from the edges of a metal workpiece [15]. A simple demonstration of the notching process is depicted in Figure 9.

The advantages of notching are:

i. Notching allows for different angle notches to be made by adjusting the location of the workpiece.

ii. It allows for different cuts to be made that are not possible to make using other shearing processes. 


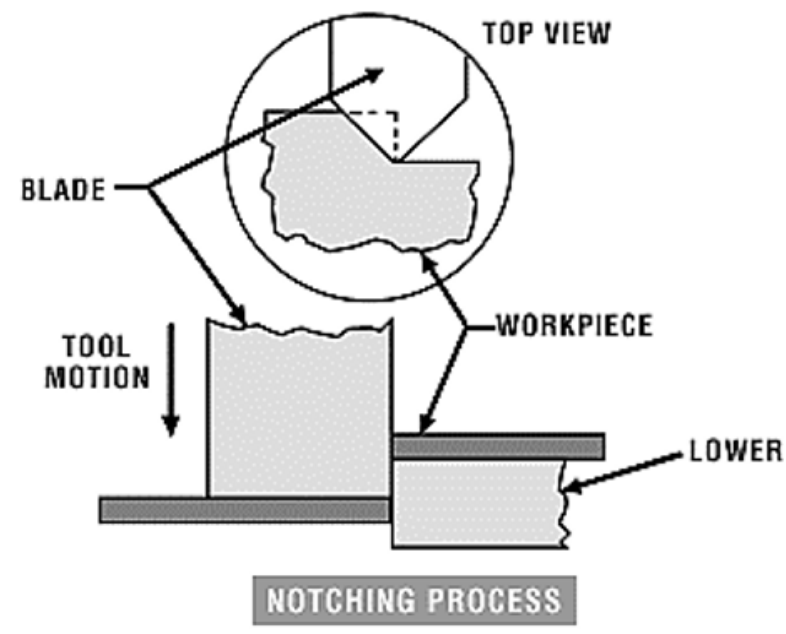

Fig. 9. Two-dimensional diagram of a notching process [15]

\section{Shearing Machines}

Shearing equipment is multi-functional machines being used to cut alloys and other sheet metals as shown in Figure 10, smaller shearing machines use scissors such as cutters or angular shearing movement to form sheet or strips of metals, larger machines are using a straight shear operation with the blade set at an angle as opposed to the angular movement. The thickness of the material to be cut [16] is a function of the rake (angular configuration of the blade) and the clearance. The normal shear consists of a fixed bed to which a blade is mounted, a vertically advancing crosshead and a set of pins or feet holding the material in place while the cutting takes place [16].

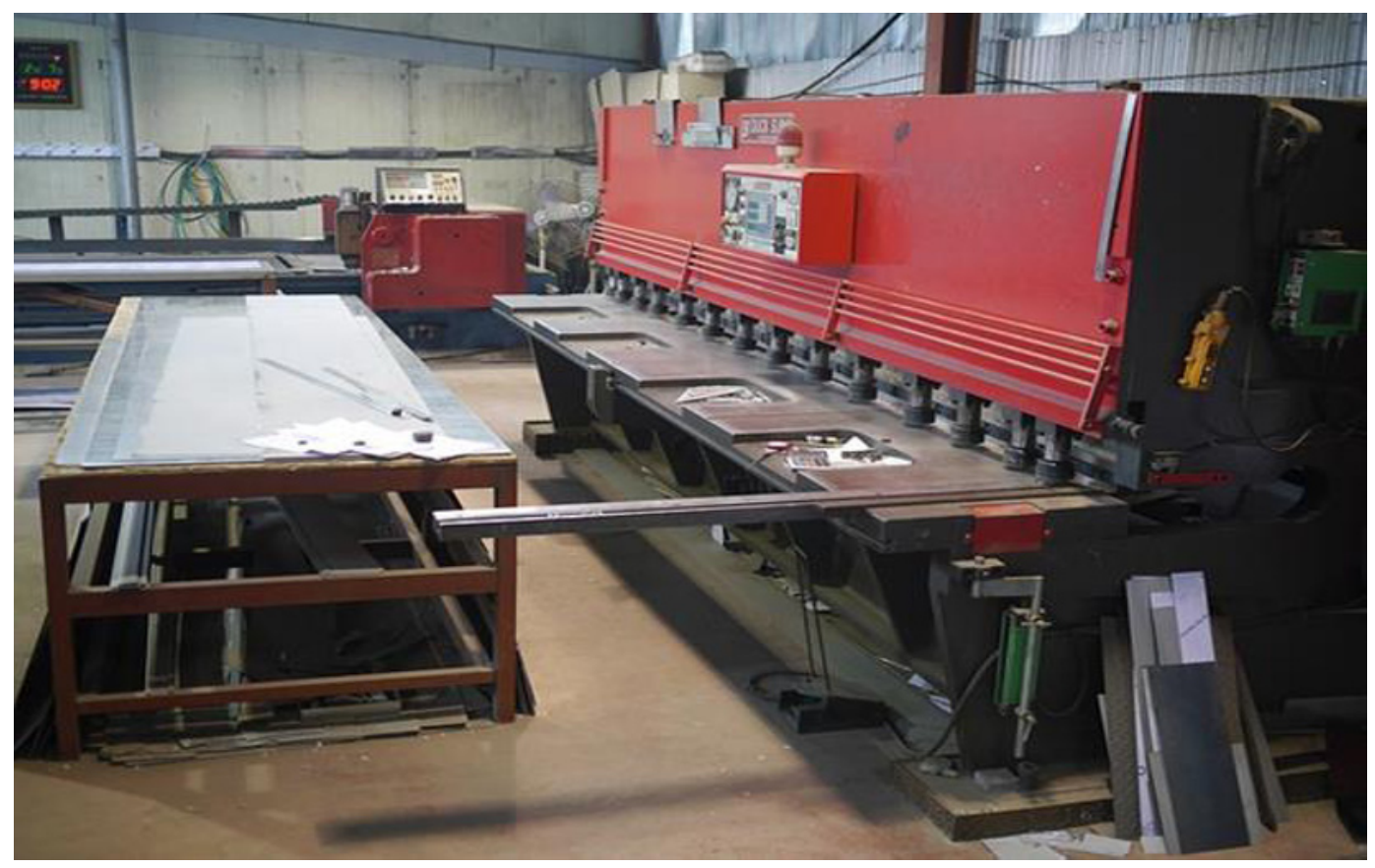

Fig. 10.A typical modern shearing machine [16]

There are different types of shearing machines, the most common ones are listed below [16]:

i. Air/pneumatic shear - use a pneumatic cylinder to power the crosshead and upper blade.

ii. Hydromechanical shears - are driven by a hydraulic cylinder or hydraulic motor.

iii. Servo driven shears - are driven by a direct connection to a servo motor.

iv. Hydraulic shears -these are driven or powered by a hydraulic cylinder. Hydraulic presses can generate extremely high forces to cut metals or other materials.

v. Mechanical shears - have the moving blade driven by a rotary motor through a screw, toggle, lever, or other mechanisms.

vi. Manual shears - these are driven or powered by hand or with the manual force that is magnified with a screw, lever, or other mechanisms.

\subsection{Ways of ensuring the optimal functionality of a shearing machine.}

The shearing process is time-consuming and requires much more labour/force in the removal of material compared to forming and shaping operations [17]. It is very important that during the operation, the process is made as perfect as it can be. The following ensures maximum functionality.

i. Make sure the blade is straight with no bends or curvatures

ii. The clearance should correspond to the type of material and its thickness

iii. Check for the back-gauge conditions

iv. Ensure the metal sheet is steady and does not move unnecessarily

v. Proper maintenance of the machine is essential this could be in the form of cleaning and/or 
replacement of components, this increases reliability, safety, and service life/lifetime [18].

When the applied shear force is large enough, the shear stress of the material will be greater than the yield shear strength resulting in the material separating a cut location. The Shearing process can be used in sheets, bars, rods, tubes, and even structural shapes. Shearing of metals makes straight-line cuts and does not burn, melt, or make chips on material after cutting on a material which is an advantage for weaker metals, like bronze, brass, low carbon steel and aluminium [19, 20]. The shearing process can be applied on any diameter workpiece and it can produce numerous pieces in a day. The most interesting thing is that it can produce minimum kerf without material loss with small tolerance $[19,20]$. Nevertheless, Shearing is not applicable for harder metals like tungsten because it is brittle, the cutting tool gets damaged over time and the metal itself can deform in an unusual way [20]. The shearing process is also cost-effective for higheroperations and it is not applicable for parts less than $3.2 \mathrm{~mm}$ in length. The metal can result in twisting depending on the clearance of the cutting tools as well as the clamping of the workpiece [20].

\subsection{Case study on how shearing processes have improved manufacturing of products}

\subsubsection{Case 1: The continuously confined strip shearing (C2S2) process}

Saving energy and producing vehicles with a lightweight has played a huge role in the development of materials. To save fuel in modern vehicles it is required that the dense steel body be replaced by a lightweight aluminium $(\mathrm{Al})$ plus with this, the vehicles will emit less $\mathrm{CO}_{2}$ into the atmosphere. Trying to replace the heavy body sheets is not an easy task as the

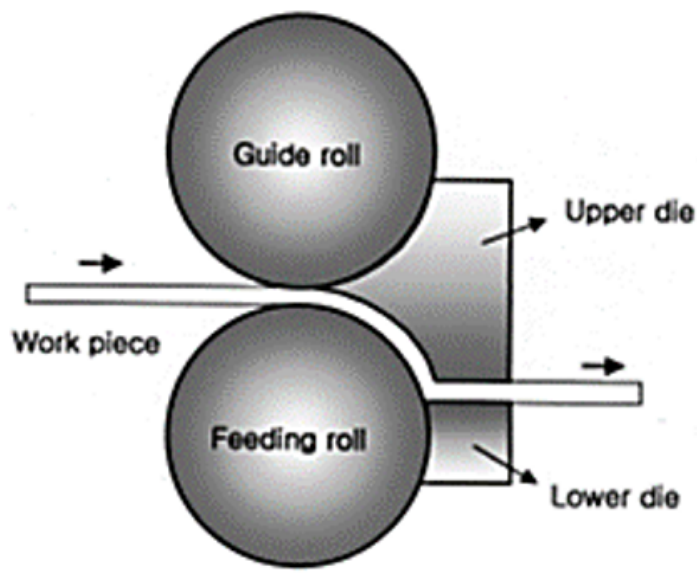

A1 steel is weaker than normal heavy sheets such as Iron. As shown in Figure 11, the average R-value of Fe base steel vs the A1 base steel.

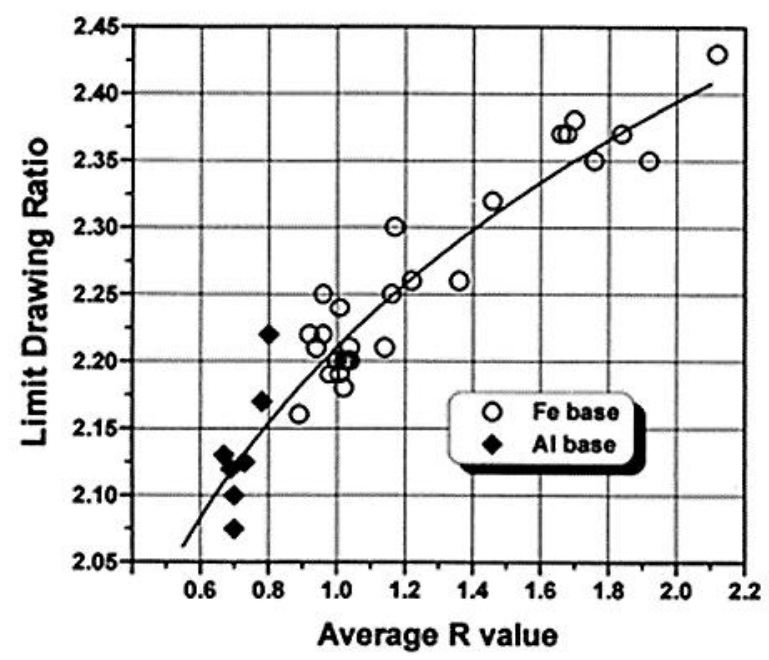

Fig. 11. A plot showing the average R-value and the limit drawing ratio of the Fe-base and the Al-base alloys [21]

BCC metals have a high R-value, and the FCC metals possess an R-value less than 1.0 then A1 alloy metals lie between $0.7 \& 0.8$, with such a low R-value they are currently the preferred metals for the exterior parts of most vehicles. A1 metals manage to get this low R-value by being fabricated through hot \& cold rolling processes which are then followed by heat treatment for texture control. Researchers found a new technique of inducing a sufficiently great amount of shear strain into the metal by using Equal Channel Angular Pressing (ECAP). What this does to metal is, it improves the shear textures and in return, the R-value of the metal is improved [21]. A typical illustration of the $\mathrm{C} 2 \mathrm{~S} 2$ process is depicted in Figure 12.

Fig. 12. The concept of the $\mathrm{C} 2 \mathrm{~S} 2$ machine used for continuously confined strip shearing based on ECAP [21]

The C2S2 process forces a shear deformation to the metal strip through the ECAP channel at the specified or required dimensions set on the machine. The machine uses a twin-roll in order to get constant operation plus that makes it more efficient than a hydraulic press. From the way the machine is set up, it is able to spot and remove metals that are affected by the roll surface [21]. 


\subsubsection{Case 2: Shearing process for copper alloy wire for Metal Zipper}

The following metal forming process is very important in the pants, shoes, bags along withthe hats industry as the zip elements used in these products are produced or made through plastically deforming the $\mathrm{Y}$-shaped copper-zinc alloy in a chain machine as shown in Figure 13.

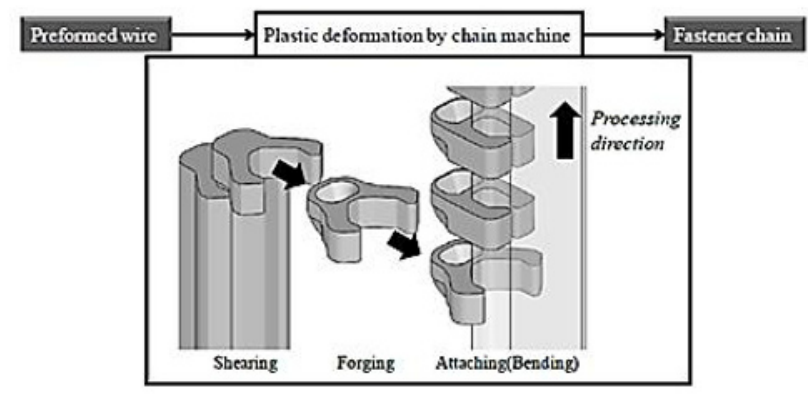

Fig. 13. Plastically Deforming a Zipper Component [22].

To begin with, the preformed wire is sheared to a little chip. At that point, the chip is forged to make an inward and protrusion. At last, the two legs of the chip get twisted to cramp a tape for the zipper. With the recent design of zippers getting more and more complex, it is very challenging to deform the copper- zinc alloy into the desired shape, therefore which comes with more trials \& errors in the manufacturing process to get the perfect shape [22].

\subsubsection{Case 3:The Shear Assisted Magnesium Alloy ZK60 Tubing}

Magnesium is a lightweight and strong material to an extent that it can be substituted in a place of steel for building structures for vehicles. Although this a good high-quality material, there are a few setbacks that are limiting magnesium as a production metal such as, its high costs \& poor mechanical properties for the cheaper magnesium (non-RE Mg). Some researchers have discovered that the non-RE $\mathrm{Mg}$ can have it mechanical properties improved with the use of Shear Assisted Processing \& Extrusion (SHAPE). The non$\mathrm{RE} \mathrm{Mg}$ could come as a solution of weight reduction in the automotive industry as this is low cost and has a moderate strength [23]. With SHAPE the uniformity of grain size \& texture through wall thickness along with other challenges that are faced by FSBE tubes can be overcome. SHAPE overcomes these challenges by allowing a certain amount of microstructure refinement, breaking down the second phases \& enabling crystallographic orientation. All of this is not possible to execute with the use of conventional techniques for extruding metals [23].

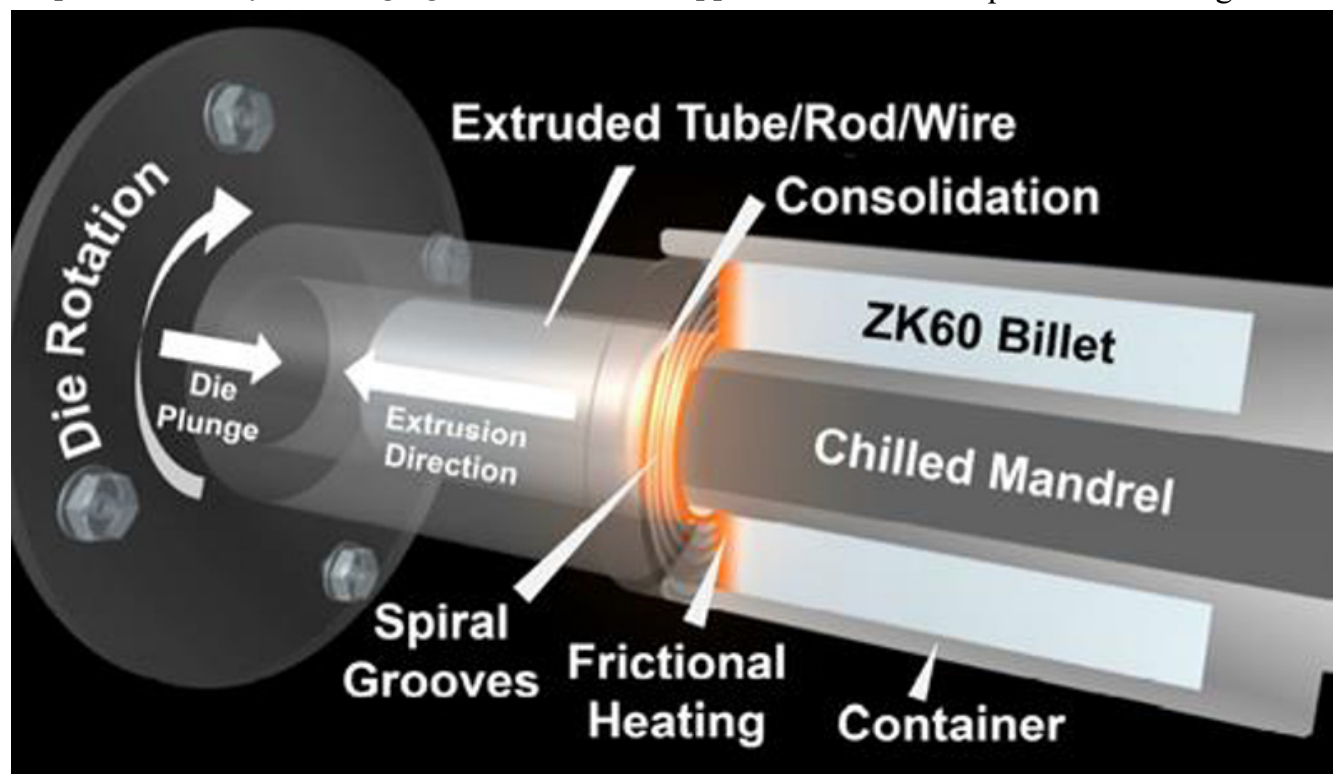

Fig. 14. The SHAPE process [23].

\section{Conclusion and Recommendation}

According to the research done, different shearing processes were outlined. It is recommended to use lengths above $3.2 \mathrm{~mm}$ when using the shearing process. The Shearing process is not recommended for hard metals, it must not be used in applications where smooth end surface finish is strictly required because it is not a burr-free cutting [2]. Recent developments such as non-RE $\mathrm{Mg}$ having its mechanical properties improved with the use of Shear Assisted Processing have been discovered [23].
The authors acknowledged Covenant University for the financial support offered for the publication of this study.

\section{References}

1. Tisza M. Int J Microstruct Mater Propert 8, 125 (2013).

2. Groover MP Principles of modern manufacturing, $5^{\text {th }}$ edn. Wiley Publisher (2013).

3. Wanisevie A, Milutinovi M, Strbac B, Skakum P. J TechnolPlast. 39, 157 (2013). 
4. Ikumapayi, O.M., Akinlabi, E.T., Onu, P., Abolusoro, O.P., Materials Today: Proceedings 26, 1644 (2020).

5. Lim Y, Venugopal R, Galip Au. Advances in control of sheet metal forming. In:proceedings of the $17^{\text {th }}$ world congress, the international federation of automatic control seoul, Korea, pp 1875 (2008).

6. Ken-ichiro Mori . J. Manuf. Mater. Process, 4, 54 (2020).

7. Al-Qureshi, H. A. Journal of Materials Processing Technology, 125, 751 (2002).

8. Hambli, R. Engineering Fracture Mechanics, 68, 365 (2001).

9. Levy, B.S.; Van Tyne, C.J.. J. Mater. Eng. Perform. 21, 1205 (2012).

10. Damerowa U, Tabakajew D, Borzykh M, Schaermann W, Homberg W, Trachler A. Procedia Technol, 15, 439 (2014).

11. Hosford WF, Duncan JL. JOM 39 (1999).

12. Shih, H.C.; Shi, M.F. ASME J. Manuf. Sci. Eng., 133, 061018 (2011).

13. Matsuno, T.; Nitta, J.; Sato, K.; Mizumura, M.; Suehiro, M. J. Mater. Process. Technol., 223, 98 (2015).

14. Bressan JD. Int J. mater Forum suppl 1, 117 (2008).

15. Ikumapayi OM, Akinlabi ET, Adeoye AOM, Fatoba SO. Material today: Proceedings., 44, 1154 (2021).

16. Afolalu SA, Ikumapayi OM, Abdulkareem A, Emetere ME, Adejumo O. Material today: Proceedings., 44, 2884 (2021).

17. Afolalu SA, Ikumapayi OM, Abdulkareem A, Soetan SB, Emetere ME, Ongbali SO. Material today: Proceedings., 44, 2895 (2021).

18. Bodunde OP, Ikumapayi OM, Akinlabi ET, Oladapo BI, Adeoye AOM, Fatoba SO. Material today: Proceedings., 44, 1144 (2021).

19. Ikumapayi, O.M., Oyinbo, S.T., Akinlabi, E.T., Madushele, N, Materials Today: Proceedings, 26, 1532 (2020).

20. Ikumapayi, O.M., Akinlabi, E.T., Mwema, F.M., Ogbonna, O.S. Materials Today: Proceedings, 26, 3275 (2020).

21. Hambli, R., Guerin, F., \& Dumon, B. The International Journal of Advanced Manufacturing Technology, 21, 483 (2003).

22. Brecher, C.; Emonts, M.; Eckert, M.; Weinbach, M. Phys. Procedia, 56, 1427 (2014).

23. Mori, K.; Maeno, T.; Fuzisaka, S. J. Mater. Process. Technol, 212, 534 (2012). 